\title{
Corrigendum to "Fiber Bragg Grating Sensors-Based In Situ Monitoring and Safety Assessment of Loess Tunnel"
}

\author{
Jinxing Lai $\mathbb{D}^{1},{ }^{1}$ Junling Qiu ${ }^{D},{ }^{1}$ Haobo Fan $\mathbb{D}^{1},{ }^{1}$ Qian Zhang, ${ }^{2}$ Zhinan Hu, \\ Junbao Wang $\left(\mathbb{C}^{3},{ }^{3}\right.$ and Jianxun Chen $\mathbb{1}^{1}$ \\ ${ }^{1}$ School of Highway, Chang'an University, Xian 710064, China \\ ${ }^{2}$ School of Civil Engineering, Shijiazhuang Tiedao University, Shijiazhuang 050043, China \\ ${ }^{3}$ School of Civil Engineering, Xian University of Architecture and Technology, Xian 710055, China \\ Correspondence should be addressed to Jianxun Chen; chenjx1969@chd.edu.cn \\ Received 20 May 2019; Accepted 28 May 2019; Published 16 June 2019
}

Copyright (c) 2019 Jinxing Lai et al. This is an open access article distributed under the Creative Commons Attribution License, which permits unrestricted use, distribution, and reproduction in any medium, provided the original work is properly cited.

In the article titled "Fiber Bragg Grating Sensors-Based In Situ Monitoring and Safety Assessment of Loess Tunnel" [1], there was an error in the Acknowledgments section, which should be corrected as follows:

"This work is financially supported by the Brainstorm Project on Social Development of Shaanxi Provincial Science and Technology Department (no. 2016SF-412), the Industrial Research Project of Science and Technology Department of Shaanxi Province (no. 2015GY185), and the Special Fund for Basic Scientific Research of Central Colleges of Changan University (no. 310821165011). The authors would like to express appreciation to the reviewers for their valuable comments and suggestions that helped to improve the quality of the paper."

\section{References}

[1] J. Lai, J. Qiu, H. Fan et al., "Fiber bragg grating sensors-based in situ monitoring and safety assessment of loess tunnel," Journal of Sensors, vol. 2016, Article ID 8658290, 10 pages, 2016. 


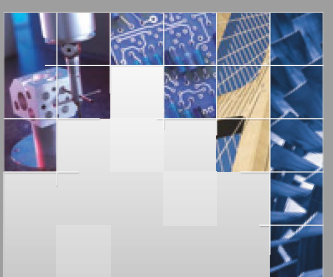

\section{Enfincering}
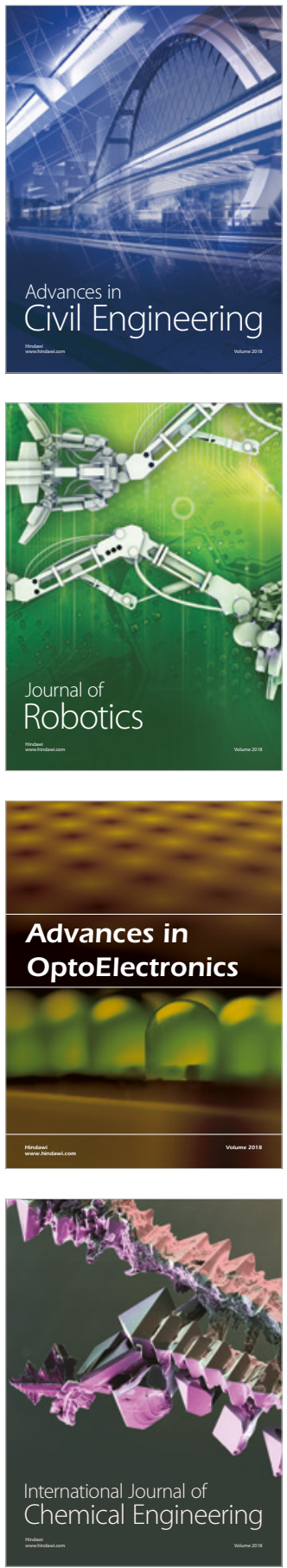

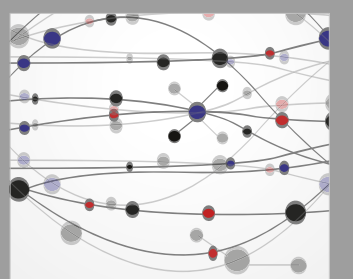

\section{Rotating \\ Machinery}

The Scientific World Journal

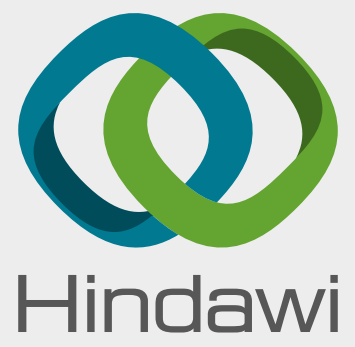

Submit your manuscripts at

www.hindawi.com
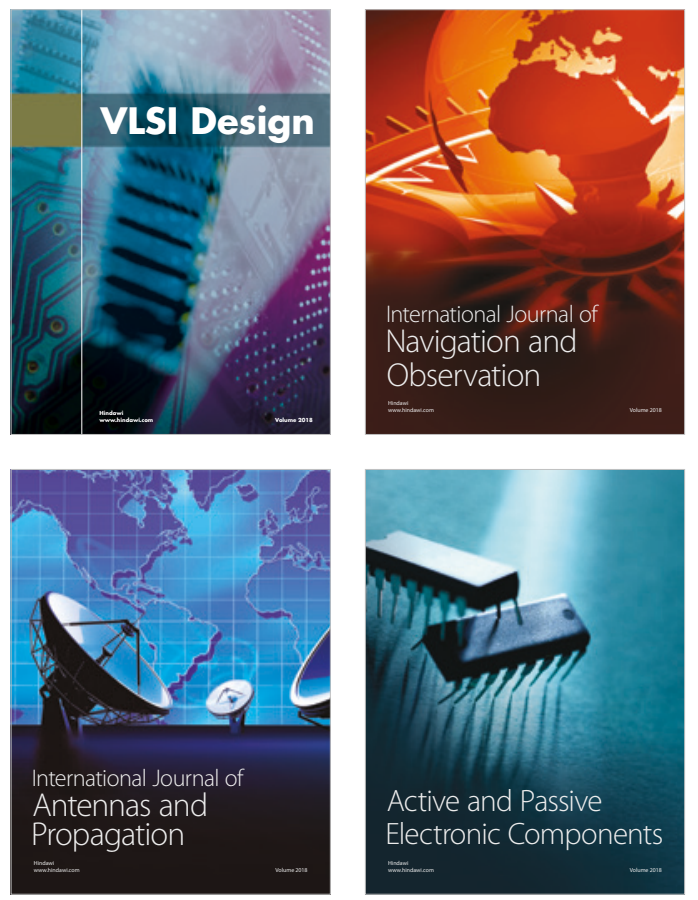
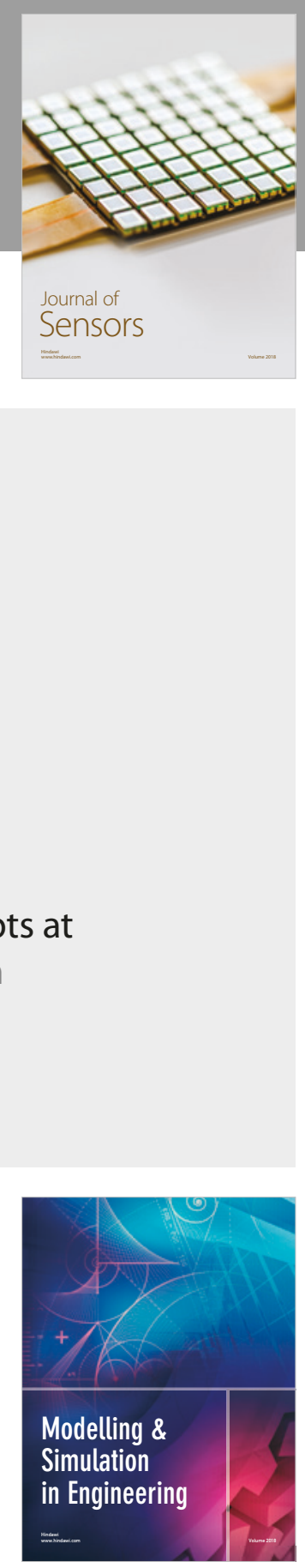

\section{Advances \\ Multimedia}
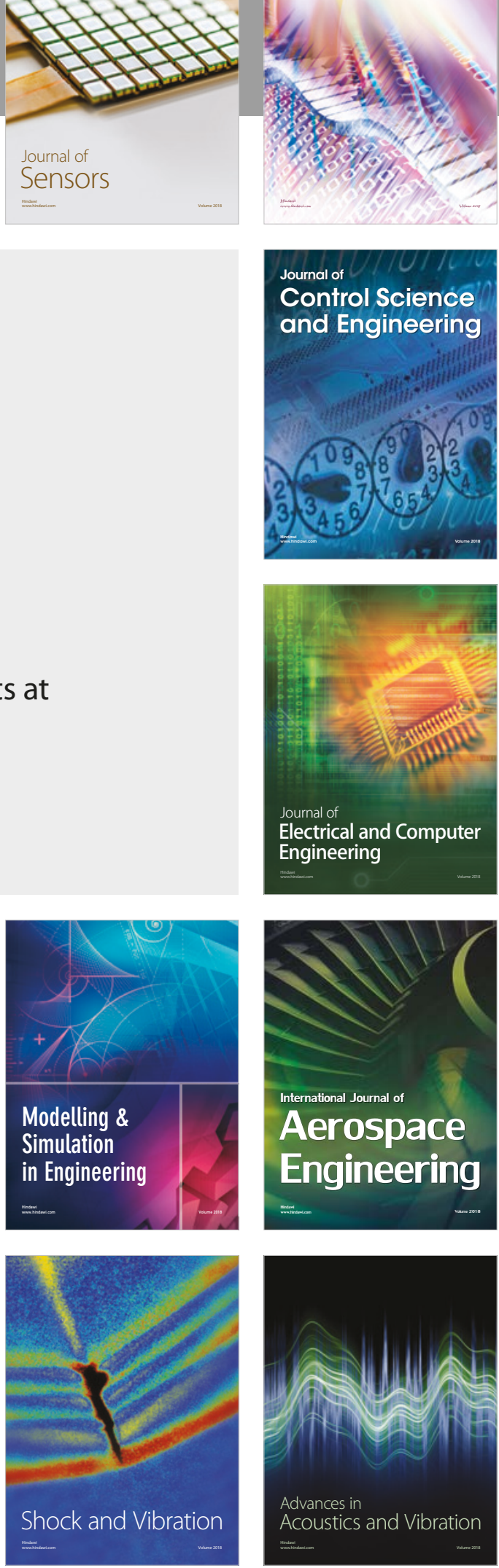